\title{
Annealing effect on the evolution of adiabatic shear band under dynamic shear loading in ultra-fine-grained iron
}

\author{
Fuping Yuan*, Ping Jiang, Xiaolei Wu \\ State Key Laboratory of Nonlinear Mechanics, Institute of Mechanics, Chinese Academy of Science, Beijing 100190, China
}

\section{A R T I C L E I N F O}

\section{Article history:}

Received 27 January 2012

Received in revised form

28 June 2012

Accepted 3 July 2012

Available online 14 July 2012

\section{Keywords:}

Adiabatic shear band

Hat-shaped specimen

Ultra-fine-grained

Equal-channel angular pressing

Dynamic shear loading

\begin{abstract}
A B S T R A C T
In the present study, evolution of adiabatic shear band (ASB) and annealing effect on the evolution of ASB in ultra-fine-grained (UFG) Fe under dynamic shear loading were investigated. The UFG Fe was processed by equal-channel angular pressing (ECAP) via route $\mathrm{B}_{\mathrm{C}}$. After 6 passes, the grain size of UFG Fe reaches $\sim 500 \mathrm{~nm}$, as confirmed by means of Transmission Electron Microscopy (TEM). Examination of microhardness and grain size of UFG Fe shows a transition from recovery to grain growth at annealing temperature of approximately $400{ }^{\circ} \mathrm{C}$. The high-strain-rate response of UFG Fe was characterized by hatshaped specimen set-up in Hopkinson bar experiments. With increased shear deformation, the evolution of ASB was found to be a two-stage process, namely a nucleation stage followed by a thickening stage. In the thickening stage, ASB evolution is accompanied by increasing in both thickness and micro-hardness of ASB. The increased micro-hardness in ASB and TEM observations inside ASB indicate that grains in the shear band are further refined. Once the shear band is initiated, cracks also nucleate and propagate within ASB, which produces failure in the material. After $450{ }^{\circ} \mathrm{C}$ post-ECAP annealing, development of ASB and crack propagation were inhibited under dynamic shear loading. The results indicated that the ductility under dynamic shear loading can be significantly improved by appropriate post-ECAP annealing without losing the strength of the UFG Fe.
\end{abstract}

(c) 2012 Elsevier Ltd. All rights reserved.

\section{Introduction}

UFG/nanocrystalline (NC) materials have unique mechanical properties, such as increased strength/hardness, improved toughness and enhanced diffusivity compared to their coarse grained counterparts [1,2]. However, UFG/NC materials usually show reduced strain hardening and limited ductility, especially under high strain rate deformation [3-11]. One of the reasons is the shear band formation during dynamic loading [7-11]. The strain rate effects in UFG/NC metals with different lattice structures have been summarized in Ref. [12]. The experimental results consistently indicate that strain rate sensitivity (SRS) of FCC metal has been remarkably enhanced in the UFG/NC regime, while that of BCC metals has been considerably reduced. UFG/NC BCC metals are prone to shear band formation due to the reduced strain-hardening rate and SRS [8-10].

Adiabatic shear band (ASB) has been recognized as an important phenomenon, as a precursor for dynamic failure, in the field of

\footnotetext{
* Corresponding author. Tel.: +86 01082544170; fax: +86 01082543977.

E-mail addresses: fpyuan@Inm.imech.ac.cn (F. Yuan), jping@imech.ac.cn (P. Jiang), xlwu@imech.ac.cn (X. Wu).
}

dynamic deformation for a large class of metals and alloys [13-17]. As for UFG/NC BCC metals, the first observation of localized deformation in the form of shear band has been reported for consolidated UFG/NC Fe under both quasi-static and dynamic compressive loading $[18,19]$. In the consolidated samples, the impurity and porosity during powder preparation and subsequent compaction are hard to exclude completely, so the formation of shear band is mainly due to such impurity and porosity, not adiabatic nature. Severe plastic deformation (SPD), such as ECAP, has been proven to be an effective method for production of bulk and fully contamination-free dense metals with sub-micron grain sizes $[20,21]$. The mechanical behavior of ultrafine-grained (UFG) Fe processed by SPD has been the subject of recent work due to their increased strength/hardness [22-26]. However, most of reported research work on UFG Fe was carried out under quasi-static loading [22-25], and few under dynamic loading [26]. Although the propensity and the properties of ASB in UFG Fe produced by ECAP have been investigated in Ref. [26], the origin and evolution of ASB in UFG Fe is still poorly understood.

In the present study, hat-shaped specimen set-ups in Hopkinson bar experiments were used to study the evolution of ASB in UFG Fe by controlling dynamic shear displacement. The thermal stability of UFG Fe was investigated by examination of micro-hardness and 


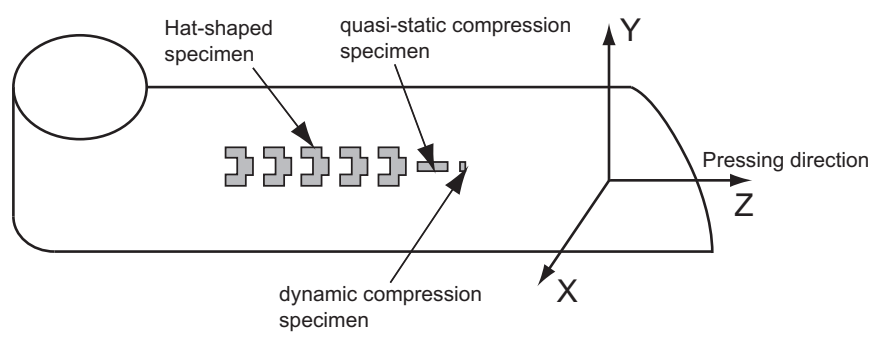

Fig. 1. Schematic illustration of the ECAP specimen geometry. $Z$ represents the pressing direction, $X$ and $Y$ represent the transverse directions.

grain size as a function of post-ECAP annealing temperature. The annealing effect on the development of ASB in UFG Fe was also studied. The results of the present paper will help to not only understand the origin and characteristics of ASB in UFG BCC metals, but provide insights for improving ductility in such materials.

\section{Materials and experimental procedures}

The hot rolled commercial pure iron used in the present study was received in the form of rods of $60 \mathrm{~mm}$ in diameter. The asreceived materials have a composition, in weight percentage, of 0.004 C, 0.01 Si, 0.2 Mn, 0.013 P, 0.007 S, 0.15 Al, 0.1 Cr, 0.002 Ni, 0.2 $\mathrm{Cu}$, and the balance of Fe. The hot-rolled billets were first annealed at $800{ }^{\circ} \mathrm{C}$ for $2 \mathrm{~h}$. Then the rods with a length of $180 \mathrm{~mm}$ were processed using an ECAP die with an interior channel angle of $90^{\circ}$ and an external arc curvature of $30^{\circ}$, which yielding an effective strain of $\sim 1$ by a single pass. The samples were extruded for six passes at $350^{\circ} \mathrm{C}$ using route $\mathrm{B}_{\mathrm{C}}$. In route $\mathrm{B}_{\mathrm{C}}$ the sample is rotated $90^{\circ}$ about its longitudinal axis after each pass. Route $B_{C}$ is the best route for achieving homogeneous properties among four fundamental routes $\left(A, B_{A}, B_{C}\right.$ and $\left.C\right)$. Details of the experimental set-up for ECAP can be found in Ref. [27]. All samples for mechanical testing were machined from the extruded billets by wire saw with loading direction parallel to the direction of pressing ( $Z$ direction in Fig. 1 ). By ignoring the head and tail regions of the pressing billets, the magnitude of experienced shear strain along the pressing direction during ECAP is nearly homogeneous [28,29]. By cutting all samples from the center region of cross-sectional plane (as shown in Fig. 1), the heterogeneity of the experienced strain along transverse directions ( $X, Y$ directions) during ECAP is also minimized [28,29].

After ECAP, the grain size of ECAP-6 Fe was examined by TEM in both parallel and perpendicular planes to the $Z$ direction. Disks for
TEM were cut with a thickness of $300 \mu \mathrm{m}$ and polished down to $50 \mu \mathrm{m}$ using 2000 grid SiC papers. Final thinning to electron transparency was achieved by jet polishing with a solution of $5 \%$ perchloric $+95 \%$ acetic acid at $-40{ }^{\circ} \mathrm{C}$. The thermal stability and the grain size of UFG Fe as a function of post-ECAP annealing temperature were also examined by micro-hardness testing and Electron Back Scatter Diffraction (EBSD). Small pieces of ECAP-6 Fe were annealed for half hour at different temperatures. The annealed sample surfaces ( $X$ plane) were polished with $0.5 \mu \mathrm{m}$ diamond paste and then were etched with $5 \%$ Nital to reveal the microstructure. For each annealing temperature, the Vickers microhardness (HV) was measured on the etched surface using a micro-hardness tester under a load of $10 \mathrm{~g}$, for $15 \mathrm{~s}$ dwell time.

Following the ASTM standards, the specimens for quasi-static compression have a length to width aspect ratio of 2.5 , and the specimens for dynamic compression (rectangular shape) have a length to width aspect ratio of 0.6 . The quasi-static compression tests were performed at strain rates of $5 \times 10^{-4} / \mathrm{s}$, while the dynamic compression experiments were performed at strain rates of $\sim 1 \times 10^{4} / \mathrm{s}$. The hat-shaped specimen set-up for Hopkinsonbar testing is shown in Fig. 2. The hat-shaped design has been widely used to study ASB in various metals [11,30-32]. The hat shape is designed to concentrate shear deformation in a narrow zone facilitating the shear band formation [11]. Details of the Hopkinson-bar technique can be found in [33]. Following impact, the hat-shaped specimens were sectioned in half along the impact axis. The half sections were then polished to 2000 grit and then polished with $0.5 \mu \mathrm{m}$ diamond paste. This was followed by etching with $5 \%$ Nital. The etched half sections were then examined by optical micrograph and SEM. Micro-hardness measurements were also made on these polished half sections using a Vickers diamond indenter at a load of $10 \mathrm{~g}$ for $15 \mathrm{~s}$ dwell time. The light load is especially compatible with measurements within ASB which have widths ranging from roughly $35 \mu \mathrm{m}-200 \mu \mathrm{m}$. Three groups of measurements traversing an ASB were made, and the average value was taken for reducing the physical error. Samples for TEM observations near ASB were cut with a thickness of $300 \mu \mathrm{m}$ along the $X$ direction, and then polished down to $50 \mu \mathrm{m}$ using 2000 grid SiC papers. To assure specific locations, the surfaces were etched with $5 \%$ Nital and examined by optical microscope. This is very important in locating regions within and/or adjacent to ASB. $3 \mathrm{~mm}$ TEM disks could be punched with ASB near the center location. Since electropolishing creates a hole in the center of $3 \mathrm{~mm}$ disks, this ensures that a region around the shear band could be examined under TEM.

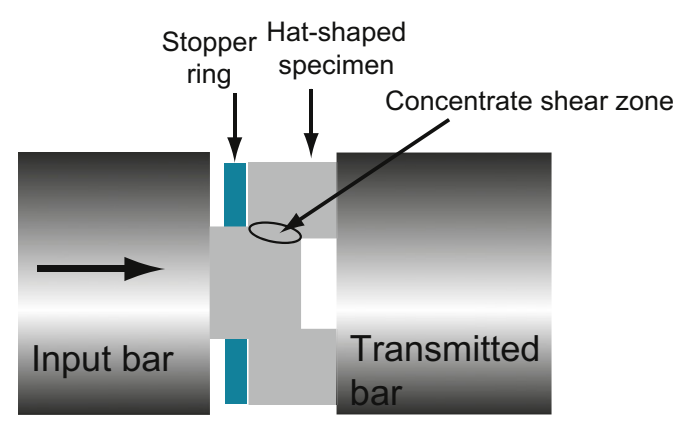

Hat-shaped specimen set-up in Hopkinson bar experiments

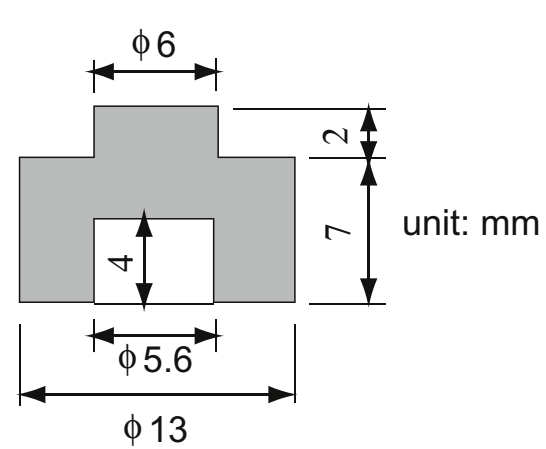

Geometry and dimensions
of hat-shaped specimen

Fig. 2. Hat-shaped specimen set-up in Hopkinson bar experiments. 

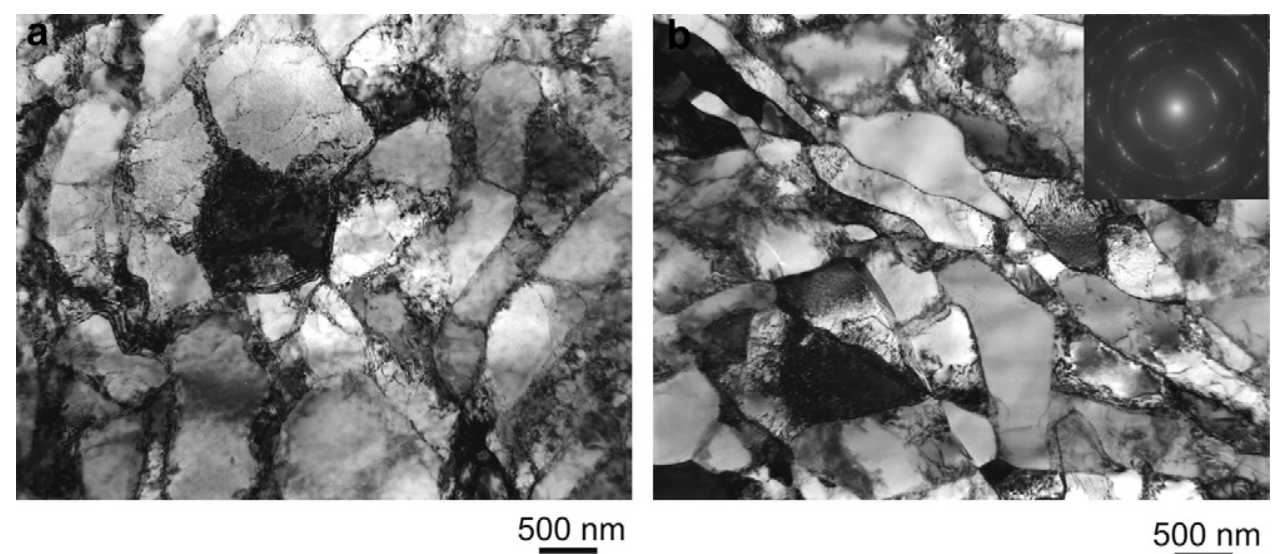

Fig. 3. TEM micrographs of microstructure after 6-pass pressing for (a) $Z$ plane; (b) $X$ plane. The insert in (b) is the corresponding SAD pattern.

\section{Results and discussions}

\subsection{Thermal stability of ECAP-6 Fe}

After pressing for six passes, the grains were sufficiently refined to sub-micron level. The typical TEM micrographs inspected on $Z$ and $X$ planes are shown in Fig. 3a and b respectively. The corresponding selected area diffraction (SAD) pattern for $X$ plane is also shown in the inset of Fig. 3b. The ultra-fine grains appear almost equiaxed on the $Z$ plane with clear fringes of grain boundaries, while the ultra-fine grains show slightly band structure on the $X$ plane. The average grain size is about $500 \mathrm{~nm}$. The evolution of micro-hardness of ECAP-6 Fe after annealing for half hours at different temperatures is shown in Fig. 4. The micro-hardness measurement is made on the surface perpendicular to the direction pressing. There is no significant change of micro-hardness when the annealing temperature is below $400{ }^{\circ} \mathrm{C}$. The microhardness decreases with increased annealing temperature above $400{ }^{\circ} \mathrm{C}$, revealing a transition from recovery to grain growth. As shown in Fig. 5, the microstructure consists of mostly large grain and the average grain size is approximately $12 \mu \mathrm{m}$ after annealing at temperature of $600{ }^{\circ} \mathrm{C}$, which has a good correlation with the micro-hardness examination.

Fig. 6a presents the true stress-strain curves obtained during both quasi-static and dynamic compression loadings for both ECAP Fe and post-ECAP annealing Fe at $450{ }^{\circ} \mathrm{C}$ (half hour). Under quasistatic loading, the ECAP Fe behaves like a nearly elastic-perfectly plastic material. The yield strength is found to decrease slightly from $480 \mathrm{MPa}$ to $450 \mathrm{MPa}$ during the annealing process, while the post-ECAP annealing $\mathrm{Fe}$ shows strain hardening due to the annealing effect. Under dynamic loading, the flow stress of ECAP Fe is increased by a factor of 1.8 compared to the quasi-static case, while flow softening behavior is observed. The adiabatic temperature rise during dynamic compression is a function of the flow stress level and the cut-off plastic strain. The calculation leads to about $200 \mathrm{~K}$ temperature rise assuming $90 \%$ of the plastic work converted into heat, so the flow softening behavior could be explained by the adiabatic heating and subsequent thermal softening during dynamic loading. Under dynamic loading, the initial flow stress is found to decrease slightly from $1000 \mathrm{MPa}$ to $930 \mathrm{MPa}$ after $450{ }^{\circ} \mathrm{C}$ post-ECAP annealing, however the flow softening behavior is vanished and flow hardening behavior is observed for

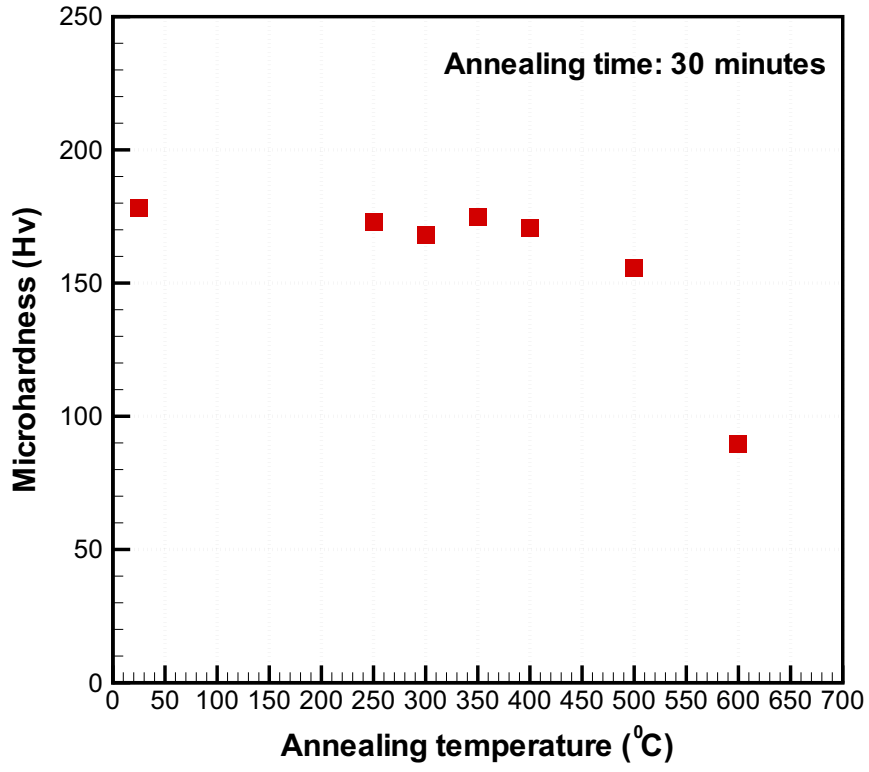

Fig. 4. Evolution of micro-hardness with annealing temperature for ECAP-6 Fe.

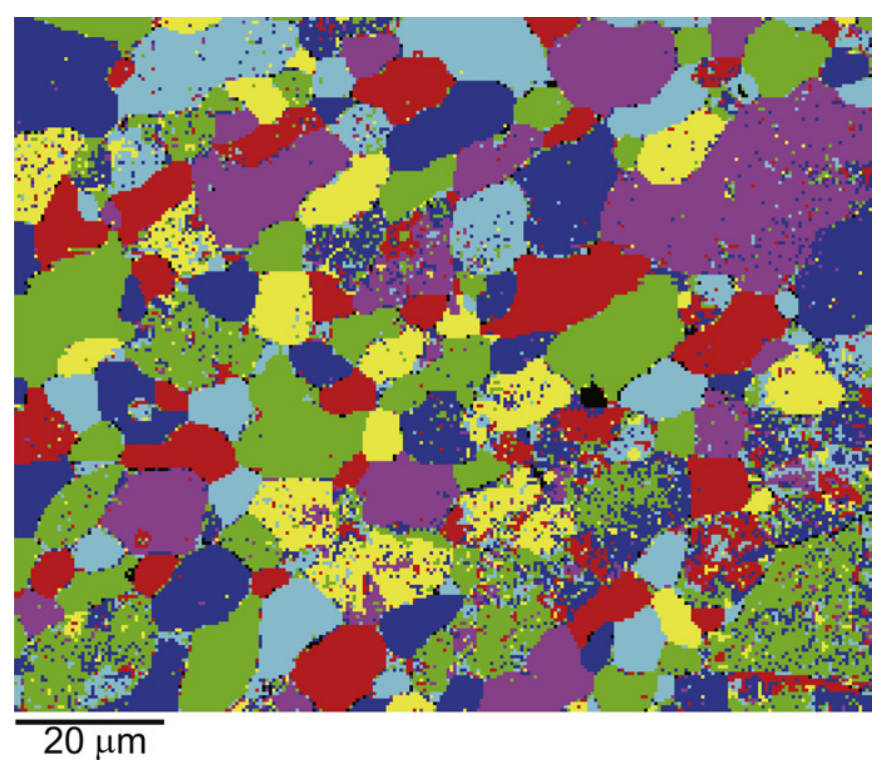

Fig. 5. EBSD map of $600{ }^{\circ} \mathrm{C}$ post-ECAP annealing Fe. 
a

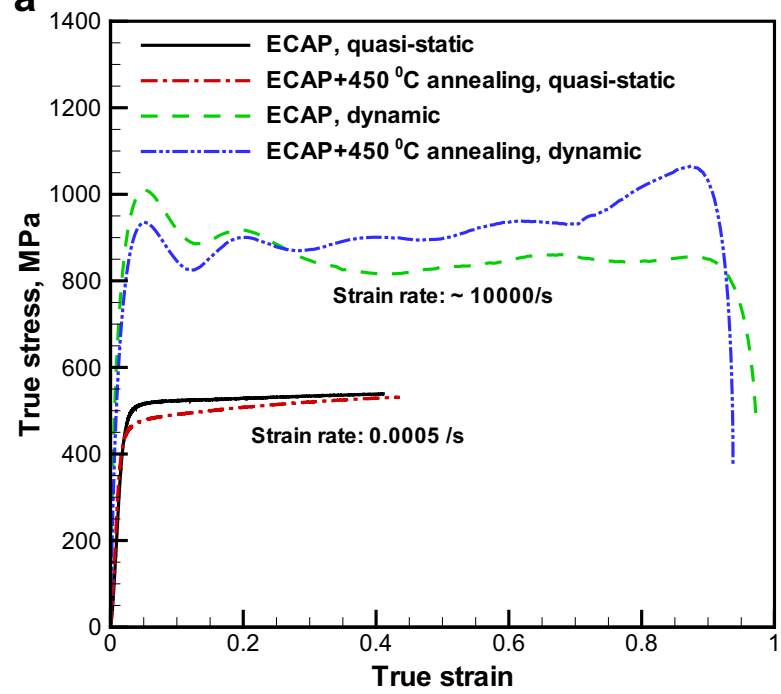

b

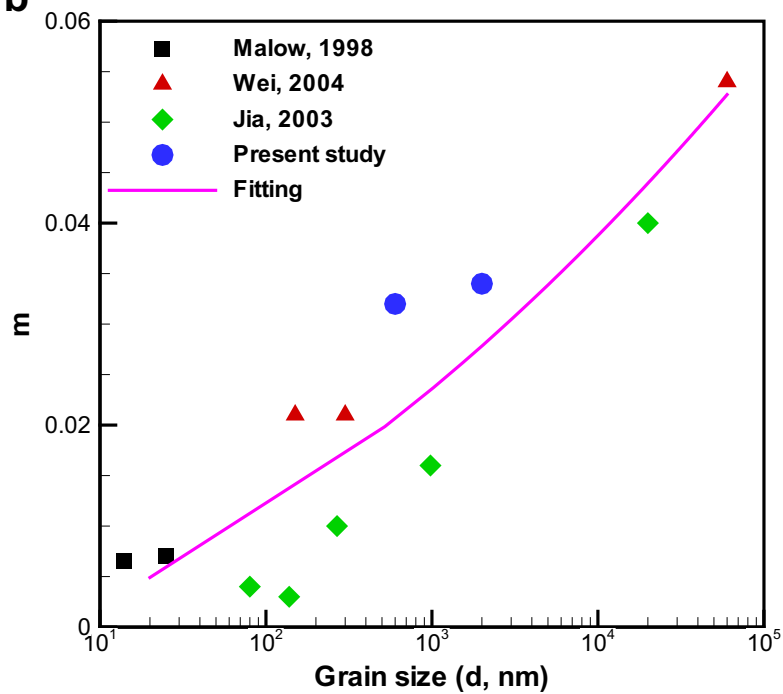

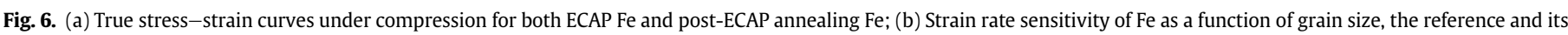
first author corresponding to each data point are also given in the plot.

post-annealed sample. This is mainly due to the fact that the increased strain hardening ability after annealing overwhelms the thermal softening effect during dynamic loading. In Fig. 6b, we plotted our data including the literature data [19,26,34] of SRS vs. grain size for Fe, in which SRS can be equally written in terms of uniaxial stresses and strains such as $m=\partial \ln \sigma / \partial \ln \dot{\varepsilon}$. The SRS of Fe decreases with reduced grain size, and this trend is sharply opposing to that of FCC metals [12]. These results indicate that the UFG Fe shows increased strength and reduced SRS compared to its coarse grained counterparts, and the appropriate post-ECAP annealing can prevent plastic instability with only a small loss of strength under dynamic compression loading.

\subsection{Evolution of $A S B$ under dynamic shear loading}

The shear stress-displacement curves of hat-shaped samples tested by Hopkinson bar are shown in Fig. 7. Three sets of ECAP-6

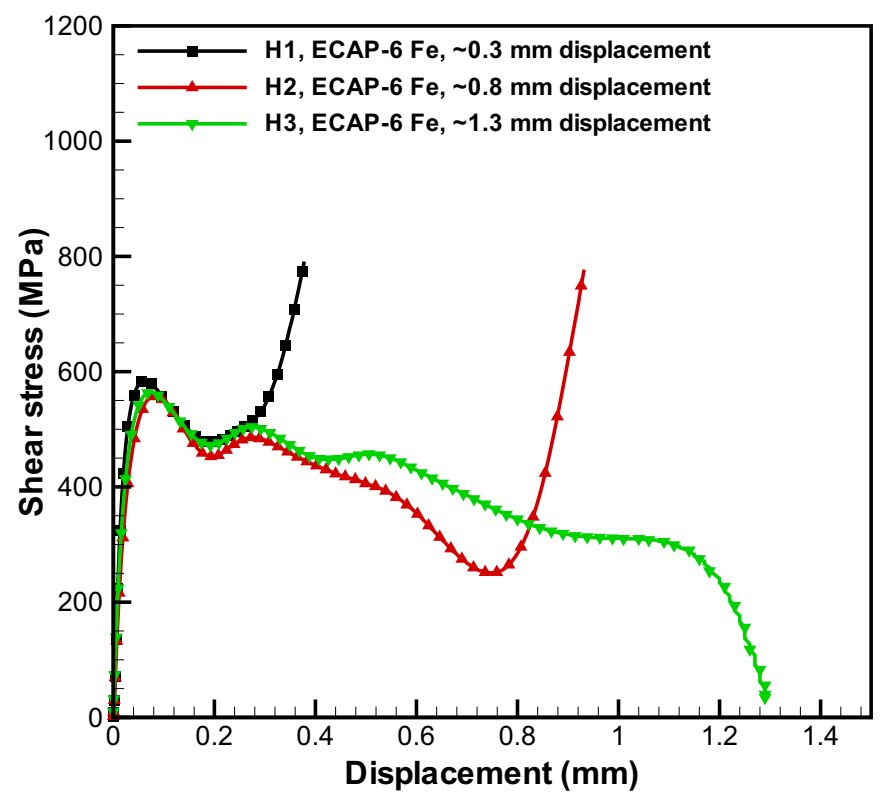

Fig. 7. Shear stress vs. displacement curves of ECAP-6 Fe specimens were tested with displacements approximately of 0.27 , 0.78 and $1.29 \mathrm{~mm}$ respectively by using stopper ring with proper thickness. These three experiments are called $\mathrm{H} 1, \mathrm{H} 2$ and $\mathrm{H} 3$ respectively. The peak shear stress for ECAP-6 Fe sample is about $550 \mathrm{MPa}$, which translates to a normal stress of $950 \mathrm{MPa}$ by Von Mises criterion. This stress level is in the same range of strength for ECAP-6 Fe as can be verified from Fig. 6a. At the end of curve H1 and $\mathrm{H} 2$, the stress rises because the incident bar is in contact with the stopper ring, the pressure is now being applied on the whole area of both the hat and the stopper ring. Increasing in shear deformation leads to loss of load capability, and the shear stress is reduced to only half of the peak shear stress when the shear displacement reaches $1.29 \mathrm{~mm}$. This load instability is due to formation of ASB, crack nucleation and propagation.

Fig. 8 shows optical micrographs of half cross-section (X plane) for experiments $\mathrm{H} 1, \mathrm{H} 2$ and $\mathrm{H} 3$. Fig. 9 shows close SEM observations of the shear band for experiments H1, H2 and H3. Fig. 10 shows Vickers micro-hardness traversing ASB for experiments $\mathrm{H} 2$ and H3. As shown in Figs. 8a and 9a, when the shear displacement is small $(0.27 \mathrm{~mm}$ for $\mathrm{H} 1)$, the shear deformation is not enough to form a shear band, but only distort the origin texture produced by ECAP. Before forming shear band, the shear strain in the hat-shaped sample can be estimated by dividing the displacement $(d)$ by the shear zone thickness $(t)$. The experienced "homogeneous" shear strains are estimated to be about $1.35(d)$ $t=0.27 / 0.2)$ and $3.9(d / t=0.78 / 0.2)$ for the experiments of $\mathrm{H} 1$ and $\mathrm{H} 2$ respectively. Since the shear band formation is observed in the experiment $\mathrm{H} 2$, but not in the experiment $\mathrm{H} 1$, the critical shear strain required for shear localization to initiate in ECAP-6 Fe is between 1.35 and 3.9. ASB has been seen in coarse-grained Armco Fe under explosive loading [15], in which the strain rate is much higher than what can be reached by dynamic shear loading used in the present study. Even at such high strain rates, the critical shear strain required for ASB in coarse-grained Armco Fe is more than 4.0. So the ECAP-6 UFG Fe investigated in the present study is much more prone to formation of ASB due to the reduced strain hardening rate and SRS.

As the shear displacement is increased, the evolution of the shear band is found to be a two-stage process, namely an initiation stage (Figs. 8b and 9b) followed by a thickening stage (Figs. 8c and 9c). In the initiation stage, the shear band occurs within a thickness 
a

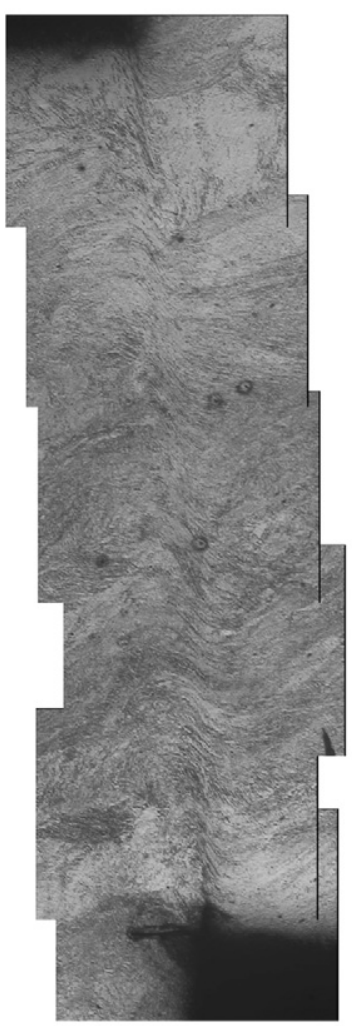

$\mathrm{H} 1$ b

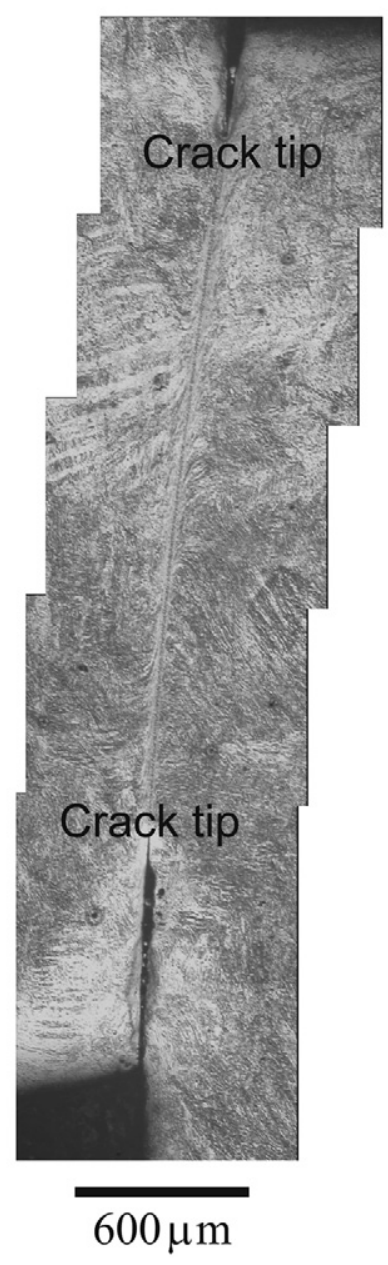

C

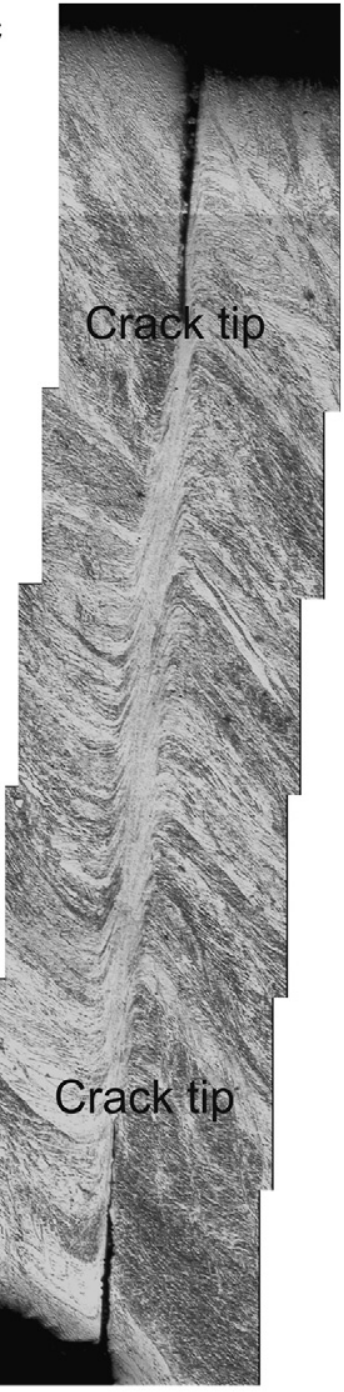

$\mathrm{H} 3$

Fig. 8. Optical micrographs of half cross-section observed for (a) $\mathrm{H} 1$; (b) $\mathrm{H} 2$; (c) $\mathrm{H} 3$.

$35 \mu \mathrm{m}$. As shown in Fig. 9b, the initial shear band consists of two regions: a core region and two transition layers. Increasing in shear deformation leads to thickening of shear bands, which is composed of thickening of the core region by transforming the transition layers into the core region, and outward movement of the transition layers by deforming the adjoining matrix. In the thickening stage, ASB evolution is accompanied by increasing in both thickness and micro-hardness of ASB. ASB width is increased from 35 to $200 \mu \mathrm{m}$, and the average micro-hardness of ASB is increased from 180 to $190 \mathrm{Hv}$ in contrast to the surrounding matrix micro-hardness of $160 \mathrm{Hv}$ (as shown in Fig. 10) when the shear displacement is increased from 0.8 to 1.3. This increased micro-hardness in ASB indicates that grains in the shear band are further refined by severe shear deformation, which is identified by TEM work shown in the Fig. 11. Fig. 11a and b represent the TEM micrographs for the asECAPed region and the shear band region respectively. The shear band region consists of the transition region and the core region. The grains in the transition region are refined from about $500 \mathrm{~nm}$ to $400 \mathrm{~nm}$. While, the grains in the core region are severely elongated and refined under the dynamic shear loading, and the average grain size in the core region is further reduced to about $280 \mathrm{~nm}$. As shown in Fig. 8b and c, micro-voids and micro-cracks in the shear band also coalesce into observable cracks which propagate along the shear bands when the shear displacement is increased. The mean crack length is increased from $0.55 \mathrm{~mm}$ to $0.80 \mathrm{~mm}$ in the thickening stage. All measurements mentioned above are also reproduced in Table 1 for summary.

\subsection{Annealing effect on the development of ASB under dynamic shear loading}

In Figs. 4 and 5, examination of micro-hardness and grain size of UFG Fe as a function of post-ECAP annealing temperature shows a transition from recovery to grain growth, and the critical transition temperature is about $400{ }^{\circ} \mathrm{C}$. In order to study the annealing effect on the development of ASB in UFG Fe, we choose $450{ }^{\circ} \mathrm{C}$ as the annealing temperature. This annealing temperature is supposed to improve the ductility of materials without losing the strength. After annealing at $450{ }^{\circ} \mathrm{C}$ for half hour, the hat-shaped specimen was investigated under dynamic shear loading with the same displacement as the experiment H3. The experiment for postECAP annealing Fe is called H4. 


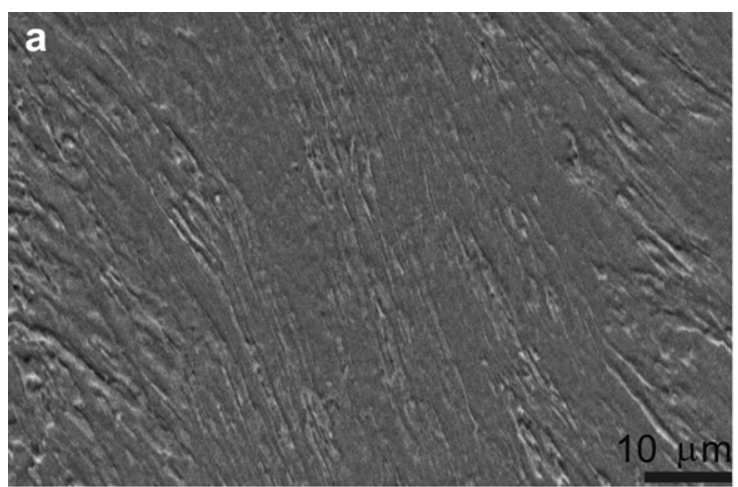

$\mathrm{H1}$

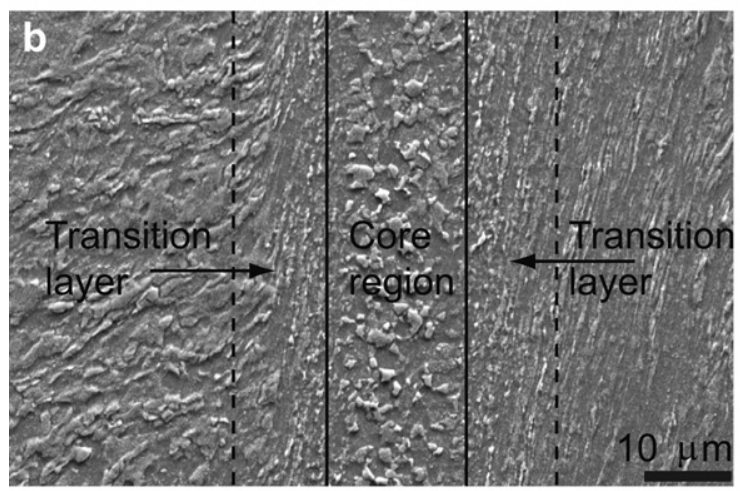

$\mathrm{H} 2$

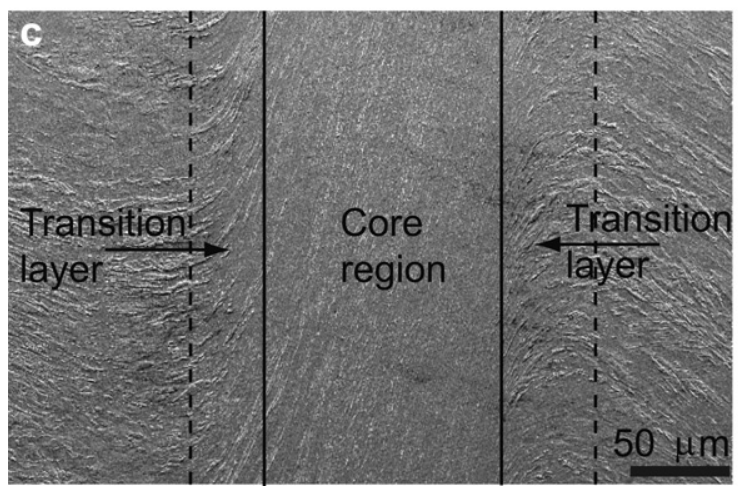

Fig. 9. SEM micrographs of the shear band as observed for (a) H1; (b) H2; (c) H3.
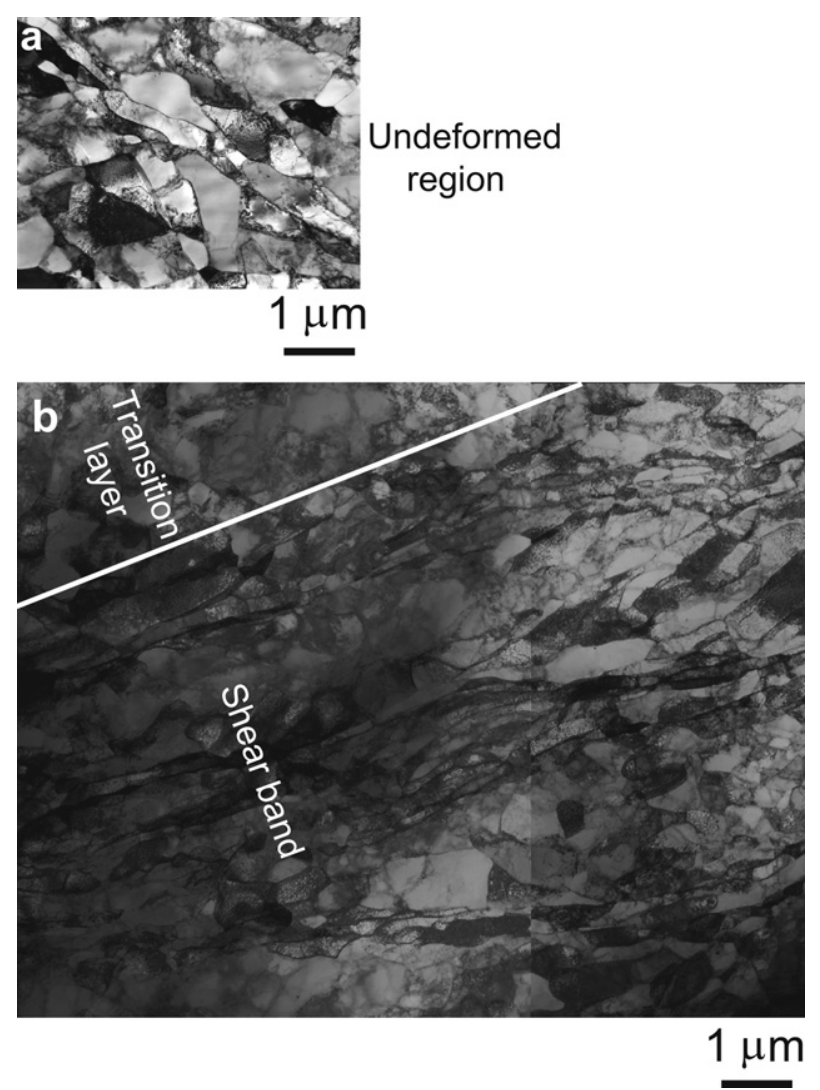

Fig. 11. TEM micrographs of microstructure on $X$ plane for (a) As-ECAPed region; (b) shear band region.

Fig. 12 shows the shear stress-displacement response of ECAP-6 Fe and post-ECAP annealing Fe. The total shear displacements are both approximately $1.2 \mathrm{~mm}$. After annealing, the peak shear stress is slightly decreased from $560 \mathrm{MPa}$ to $530 \mathrm{MPa}$, while the load instability is much inhibited due to the annealing effect. As the shear deformation is increased, the shear stress is only decreased from $530 \mathrm{MPa}$ to $490 \mathrm{MPa}$ for post-ECAP annealing Fe. Considering the area below the shear stress vs. displacement curve as the ductility of materials, the ductility of ECAP-6 Fe is significantly improved by proper thermal treatment without much losing of strength.
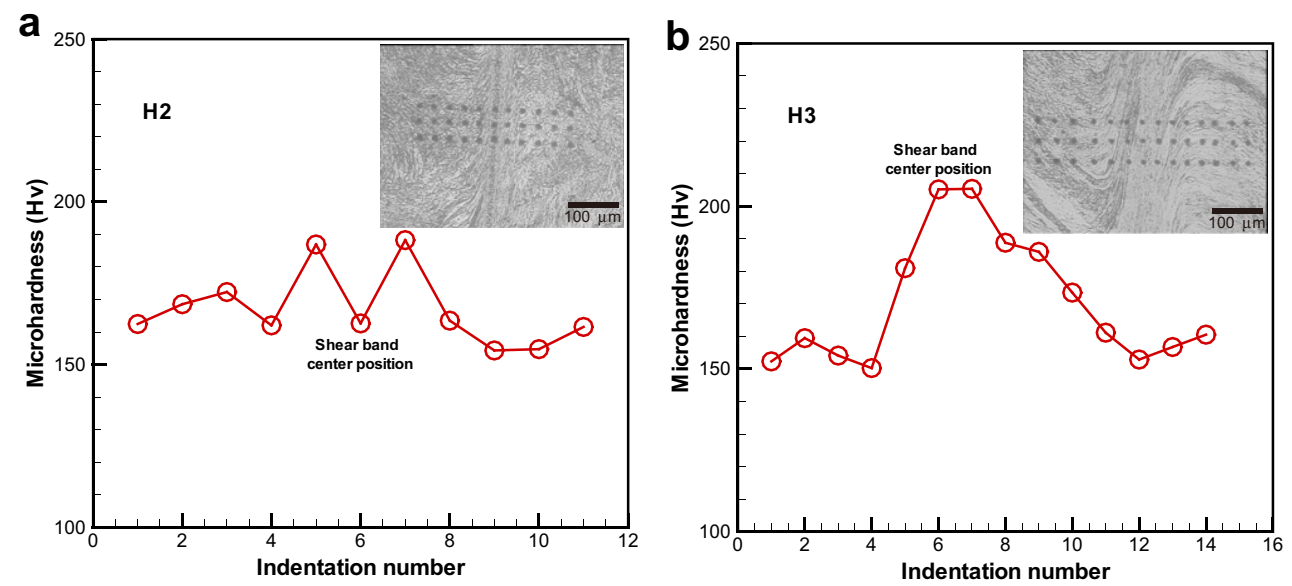

Fig. 10. Vickers micro-hardness traversing an ASB (shown in inserts) for (a) H2; (b) H3. 
Table 1

Adiabatic shear band (ASB) and deformation related properties measured in ECAP-6 Fe.

\begin{tabular}{lllll}
\hline $\begin{array}{l}\text { Experimental } \\
\text { no. }\end{array}$ & $\begin{array}{l}\text { Shear } \\
\text { displacement } \\
(\mathrm{mm})\end{array}$ & $\begin{array}{l}\text { Ave. ASB } \\
\text { width }(\mu \mathrm{m})\end{array}$ & $\begin{array}{l}\text { Mean crack } \\
\text { length }(\mathrm{mm})\end{array}$ & $\begin{array}{l}\text { Ave. ASB } \\
\text { hardness } \\
(\mathrm{Hv})\end{array}$ \\
\hline $\mathrm{H} 1$ & 0.27 & 0 & 0 & $\mathrm{~N} / \mathrm{A}$ \\
$\mathrm{H} 2$ & 0.78 & 35 & 0.55 & 179.5 \\
$\mathrm{H} 3$ & 1.29 & 200 & 0.80 & 190.0 \\
\hline
\end{tabular}

Fig. 13 shows optical micrographs of half cross-section and close SEM observations of ASB for the experiment H4. As shown in Figs. 8c, 9c and 13, the annealing treatment suppresses the evolution of ASB in the material. The average ASB width is decreased from $200 \mu \mathrm{m}$ to $135 \mu \mathrm{m}$, and the transition layers is much less distorted after annealing. The crack propagation in the ASB is also suppressed by annealing treatment. The mean crack length is reduced from $0.8 \mathrm{~mm}$ to $0.4 \mathrm{~mm}$ after annealing.

After examining the shear stress response, the characteristics of ASB features and microstructures, we can conclude that the annealing treatment improves the ductility of material without losing much of the strength, which is achieved by suppressing the evolution of ASB and propagation of crack in the ASB. This good combination of strength and ductility is achieved by mixing up the length scales [35], specifically by creating a bimodal grain size distribution with the proper heat treatment. In the bimodal structures, the large grain provides work hardening by dislocation activity in the grain interior, while the small grain provides strength. The extra strain hardening ability may come from the micro-structural length scale involved, which are close to the characteristic length scale (usually several $\mu \mathrm{m}$ ) of a material for strain-gradient plasticity to play a significant role. Because of the large strain gradient produced between the large grains and small grains, geometrically necessary dislocations required for compatible plastic strains are generated to provide additional strain hardening.

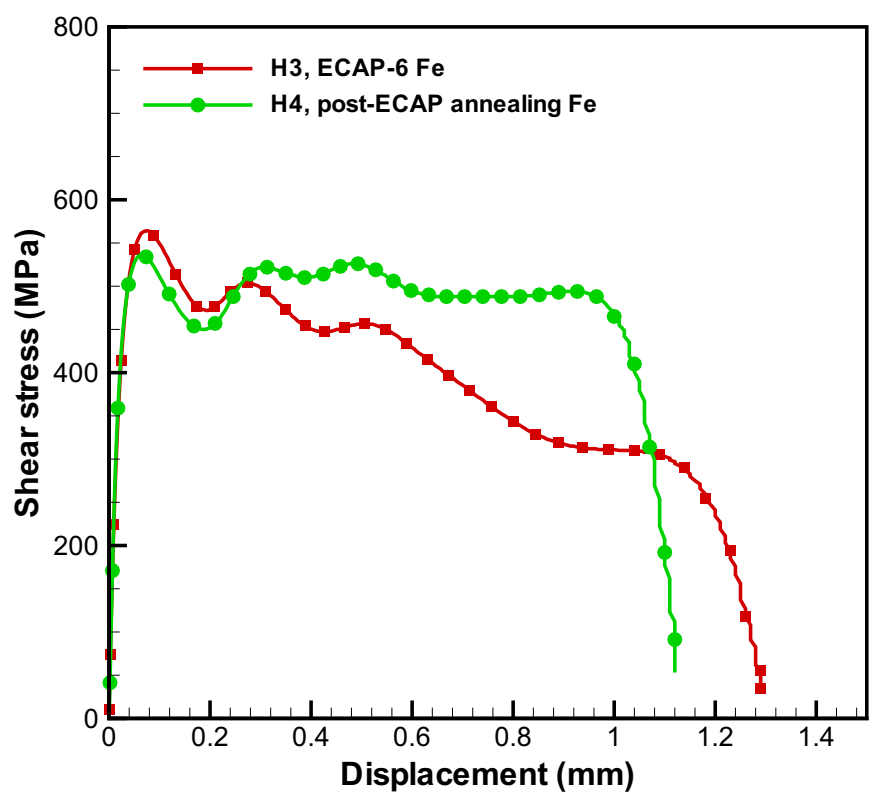

Fig. 12. Shear stress vs. displacement curves of ECAP-6 Fe and post-ECAP annealing Fe.

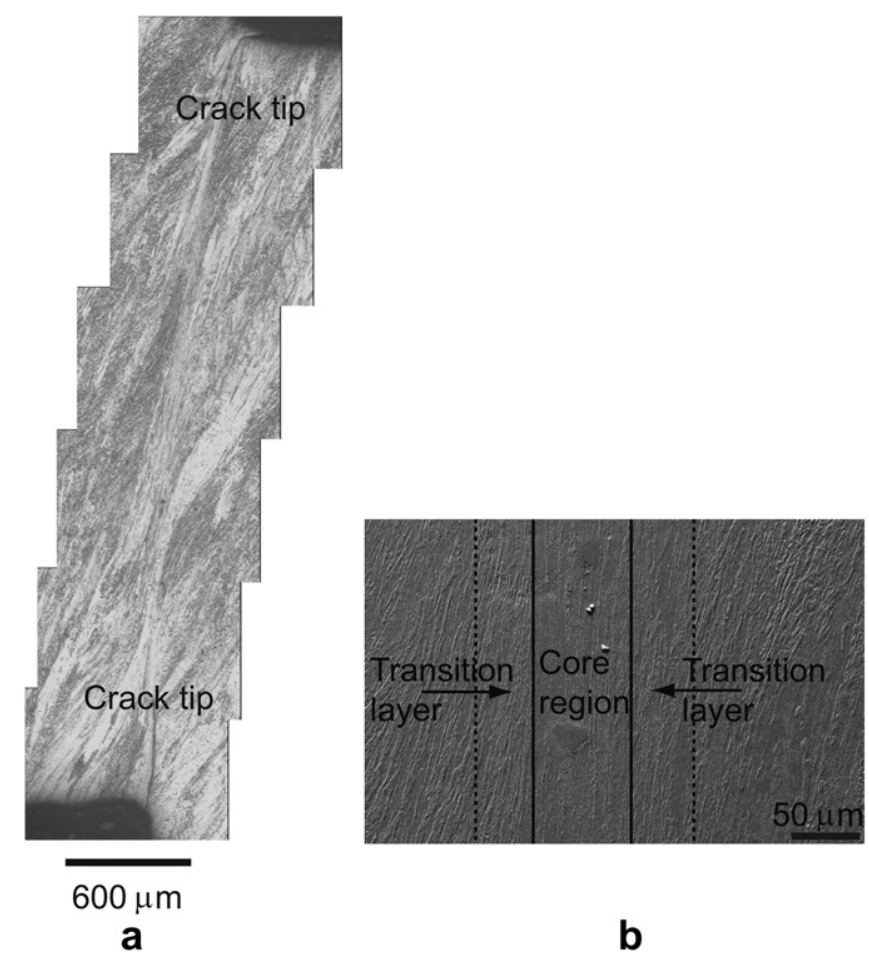

Fig. 13. (a) Optical micrographs of half cross-section observed for H4; (b) SEM micrographs of the shear band as observed for $\mathrm{H} 4$.

\section{Summary and concluding remarks}

The thermal stability, evolution of ASB and annealing effect on the development of ASB in ECAP-6 Fe were investigated systematically. The concluding remarks are as follows:

1. With increased annealing temperature, ECAP-6 Fe shows a transition from recovery to grain growth, and the critical transition temperature is approximately $400{ }^{\circ} \mathrm{C}$. The quasistatic and dynamic compression results indicate that the appropriate post-ECAP annealing can improve strain hardening and prevent plastic instability with only a small loss of strength under dynamic compression loading.

2. The ECAP-6 Fe is much more prone to formation of ASB due to the reduced strain hardening rate and SRS compared to its coarse-grained counterparts. With increased shear deformation, the development of ASB under dynamic shear loading was found to be a two-stage process, namely a nucleation stage followed by a thickening stage. In the thickening stage, ASB evolution is accompanied by increasing in both thickness and micro-hardness of ASB. ASB width is increased from 35 to $200 \mu \mathrm{m}$, and the average micro-hardness of ASB is increased from 180 to $190 \mathrm{Hv}$ in contrast to the surrounding matrix micro-hardness of $160 \mathrm{Hv}$. This increased micro-hardness in ASB and TEM observations inside ASB indicate that grains in the shear band are further refined. Once the shear band is initiated, cracks also nucleate and propagate within the ASB, which produces failure in the material. The mean crack length is increased from $18.3 \%$ to $26.7 \%$ of the ASB length in the thickening stage.

3. After $450{ }^{\circ} \mathrm{C}$ post-ECAP annealing, development of ASB and crack propagation are inhibited under dynamic shear loading. Work hardening plays a key role in the evolution of ASB. The material after $450{ }^{\circ} \mathrm{C}$ post-ECAP annealing displays a much higher work hardening rate under both quasi-static and 
dynamic compression loading. The results indicated that the ductility under dynamic shear loading can be significantly improved by appropriate post-ECAP annealing without much losing of strength. The results of the present paper will help us to not only understand the evolution of ASB in UFG Fe, but provide insights for improving ductility in such materials.

\section{Acknowledgment}

The authors would like to acknowledge the financial support from 973 Project of China (2012CB932203, 2012CB937500 and 6138504621 ) and NSF of China (11002151 and 11072243).

\section{References}

[1] Meyers MA, Mishra A, Benson DJ. Mechanical properties of nanocrystalline materials. Prog Mater Sci 2006;51:427-556.

[2] Dao M, Lu L, Asaro RJ, De Hosson JTM, Ma E. Toward a quantitative understanding of mechanical behavior of nanocrystalline metals. Acta Mater 2007; 55:4041-65.

[3] Carsley JE, Fisher A, Milligan WW, Aifantis EC. Mechanical behavior of a bulk nanostructured iron alloy. Metall Mater Trans A 1998;29:2261-71.

[4] Suryanarayanan IR, Frey CA, Sastry SML, Waller BE, Buhro WE. Plastic deformation of nanocrystalline Cu and Cu-0.2 wt.\% B. Mater Sci Eng A 1999;264: $210-4$.

[5] Jia D, Ramesh KT, Ma E. Failure mode and dynamic of nanophase iron under compression. Scripta Mater 1999;42:73-8.

[6] Jain M, Christman T. Synthesis processing, and deformation of bulk nanophase Fe-28-A1-2Cr intermetallic. Acta Metall 1993;42:1901-11.

[7] Jia D, Wang YM, Ramesh KT, Ma E, Zhu YT, Valiev RZ. Deformation behavior and plastic instabilities of ultrafine-grained titanium. Appl Phys Lett 2001;79: $611-3$.

[8] Wei Q Ramesh KT, Ma E, Kesckes LJ, Dowding RJ, Kazykhanov VU, et al. Plastic flow localization in bulk tungsten with ultrafine microstructure. Appl Phys Lett 2005;86:101907.

[9] Wei Q Zhang HT, Schuster BE, Ramesh KT, Valiev RZ, Kecskes LJ, et al. Microstructure and mechanical properties of super-strong nanocrystalline tungsten processed by high-pressure torsion. Acta Mater 2006;54:4079-89.

[10] Wei Q Kecskes LJ. Effect of low-temperature rolling on the tensile behavior of commercially pure tungsten. Mater Sci Eng A 2008;491:62-9.

[11] Mishra A, Martin M, Thadhani NN, Kad BK, Kenik EA, Meyers MA. High-strainrate response of ultra-fine-grained copper. Acta Mater 2008;56:2770-83.

[12] Wei Q. Strain rate effects in the ultrafine grain and nanocrystalline regimes influence on some constitutive responses. J Mater Sci 2007;42:1709-27.

[13] Zener C, Hollomon JH. Effect of strain rate upon plastic flow steel. J Appl Phys 1944; $15: 22-32$

[14] Recht RF. Catastrophic thermoplastic shear. J Appl Mech (Trans ASME) 1964; 31E:189-93.
[15] Bai Y, Dodd B. Adiabatic shear localization. New York: Pergamon Press; 1992.

[16] Wright TW. The physics and mathematics of adiabatic shear bands, series: Cambridge monographs on mechanics. Cambridge University Press; 2002.

[17] Woodward RL. Material failure at high strain rates. In: Zukas JA, editor. Highvelocity impact dynamics. New York: Wiley; 1990. p. 65-125.

[18] Wei Q Jia D, Ramesh KT, Ma E. Evolution and microstructure of shear bands in nanostructured Fe. Appl Phys Lett 2002;81:1240-2.

[19] Jia D, Ramesh KT, Ma E. Effects of nanocrystalline and ultrafine grain sizes on constitutive behavior and shear bands in iron. Acta Mater 2003;51:3495-509.

[20] Iwahashi Y, Horita Z, Nemoto M, Langdon TG. The process of grain refinement in equal-channel angular processing. Acta Mater 1998;46:3317-31.

[21] Valiev R. Nanostructuring of metals by severe plastic deformation for advanced properties. Nat Mater 2004;3:511-6.

[22] Tsuji N, Ito Y, Saito Y, Minamino Y. Strength and ductility of ultrafine grained aluminum and iron produced by ARB and annealing. Scripta Mater 2002;47: 893-9.

[23] Han BQ Lavernia EJ, Mohamed A. Mechanical properties of iron processed by severe plastic deformation. Metall Mater Trans A 2003;34A:71-83.

[24] Han BQ Lavernia EJ, Mohamed A. Dislocation structure and deformation in iron processed by Equal-Channel-Angular pressing. Metall Mater Trans A 2004;35A:1343-50.

[25] Ding Y, Jiang JH, Shan AD. Plastic instability and strain rate sensitivity of ultrafine-grained iron. J Alloys Compd 2009;487:517-21.

[26] Wei Q Kecskes L, Jiao T, Hartwig KT, Ramesh KT, Ma E. Adiabatic shear banding in ultrafine-grained Fe processed by severe plastic deformation. Acta Mater 2004;52:1859-69.

[27] Yang G, Huang CX, Wang C, Zhang LY, Hu C, Zhang ZF, et al. Enhancement of mechanical properties of heat-resistant martensitic steel processed by equal channel angular pressing. Mater Sci Eng A 2009;515:199-206.

[28] Prell M, Xu C, Longdon TG. The evolution of homogeneity on longitudinal sections during processing by ECAP. Mater Sci Eng A 2008;480:449-55.

[29] Djavanroodi F, Daneshtalab M, Ebrahimi M. A novel technique to increase strain distribution homogeneity for ECAPed materials. Mater Sci Eng A 2012 535:115-21.

[30] Meyer LW, Manwaring S. Critical adiabatic shear strength of low alloy steel under compressive loading. In: Murr LE, editor. Metallurgical applications of shock wave and high-strain-rate phenomena. New York: Marcel Dekker; 1986. p. 657-74.

[31] Xu YB, Zhong WL, Chen YJ, Shen LT, Liu Q, Bai YL, et al. Shear localization and recrystallization in dynamic deformation of 8090 Al-Li alloy. Mater Sci Eng A 2001;299:287-95.

[32] Lins JFC, Sandim HRZ, Kestenbach HJ, Raabe D, Vecchio KS. A microstructura investigation of adiabatic shear bands in an interstitial free steel. Mater Sci Eng A 2007;457:205-18.

[33] Sunny G, Yuan F, Lewandowski JJ, Prakash V. Design of inserts for splitHopkinson pressure bar testing of low strain-to-failure materials. Exp Mech 2009;49:479-90.

[34] Malow TR, Koch CC. Mechanical properties, ductility, and grain size of nanocrystalline iron produced by mechanical attrition. Metall Mater Trans A 1998;29A:2285-95.

[35] Ma E. Eight routes to improve the tensile ductility of bulk nanostructured metals and alloys. JOM 2006;58:49-53. 